\title{
Anthropotechnical technologies for monitoring engineering systems
}

\author{
Ruben $\operatorname{Kazaryan}^{l *}$ \\ ${ }^{1}$ Moscow State University of Civil Engineering, 129337, 26, Yaroslavskoe shosse, Moscow, Russia
}

\begin{abstract}
One of the important components of monitoring buildings and structures is an instrumental quantitative assessment of the dynamics of changes in values for all estimated parameters of the technical condition of engineering systems. In the theory of infographics, schematisms (infographic models) are considered intermediate formations of consciousness, mediating sensuality and intellect, whose roots are in the imagination. From an analytical point of view, there is a two-dimensional Euclidean space of phase states, in which the coordinates are "intentions/functions" and "institutions/traditions", and the "points/phases" are anthropic states (modes, positions, anthroponyms, etc.). The latter can be understood both in the singular sense (human in the singular) and in the collective sense (human as a community, "species being"). In general, this phase space represents the process of "culture-anthropo-psychogenesis" (anthropic synthesis). Determining what to consider the object of study (phase, technique or institution) is a matter of cultural and anthropotechnical functional literacy, and not of evaluation or choice. In addition, everyone must first understand: • Is individual-oriented or grouporiented psychotherapy possible? • What is its "functional equivalent", as a very important concept of "functional analysis"? - What in the nature of phase anthropic space blocks the appearance of such a "functional equivalent"? - What resists such innovation? - Is "psychotechnical typology" an element of "anthropotechnics"?
\end{abstract}

\section{Introduction}

Nowadays, almost all industrialized countries have entered a new stage in the development of management, which is closely related to the implementation of quality management systems. The presence in the organization of a quality management system created in accordance with the requirements of international standards ISO 9000 is the face of the organization, the guarantor of the quality of its products, indicates a high level of production culture. Customers and investors want to deal with such organizations. It is such organizations that are competitive. The quality management system is considered as a guarantee that the manufacturer is able to fulfill the requirements of the contract (agreement) and ensure the standardized quality of products (services), including

\footnotetext{
${ }^{*}$ Corresponding author: r.kazarian@mail.ru
} 
construction products. Ensuring the standardized quality of construction products at all stages of the life cycle is one of the main factors in the success of any construction organization, an effective way to increase revenue by reducing unproductive expenses for fixing defects, reducing penalties for low quality, and warranty repair costs. Improving the quality of construction products - special-purpose facilities, constructed buildings and structures, as well as road construction, is a fundamental requirement of the construction industry.

Every year the construction industry abroad shows the successful practice of using BIM-technologies. Developing at a rapid pace, the BIM concept helps simplify processes at every stage of an investment project: from design, construction and operation to reconstruction and demolition. The main core here are research institutes and government agencies that should set the vector for the development of the industry and encourage individual participants in investment and construction activities. The change of value attitudes, some forms of activity organization by others, leaves unresolved question that is the more significant for a researcher -how to form a new generation of elements of anthropotechnical monitoring technologies covering the modern specifics of anthropology. Systemic pragmatic (SP) anthropology and its associated set of anthropotechnical systemforming concepts are one of the few technological versions of the humanitarian paradigm in technical education, which allows going beyond the boundaries of ideological and value, forming two types of anthropotechnical representations within the framework of the SPmethodology: • "club"; • "collective thinking". In an anthropological perspective, both of these ideas fix the type of space with respect to which one can meaningfully raise the question of an artificial attitude towards a human and the conditions of his individual development [1-3, 4-9]. In order to formulate a methodological approach to assessing the efficiency of the construction quality management system, it is necessary to clarify some terminological issues, which include the concepts: "construction product quality management", "construction product quality management system", "efficiency of the construction product quality management system" and others. Based on the prevailing concepts in management science, the following definitions of the previously mentioned terms can be given.

Quality management of construction products is the activity of officials of management bodies, which is aimed at ensuring compliance with the requirements (regulatory and technical documentation, consumers) for construction products.

Quality management system for construction products - a set of elements necessary for timely and high-quality performance of work at construction sites. Includes: organizational structure of a company; rights, obligations, powers and responsibilities of officials; production technology, processes of interaction between units, and military units with customers and suppliers, control and assessment of products and processes, logistics of processes, personnel training.

To solve this problem, taking into account the above disadvantages, an approach to a multi-criteria assessment of the system efficiency is of interest. In matters of efficiency, it is necessary to clarify one more fundamental concept - "Effect".

The effect is a positive manifestation of something. An example of the economic effect: profit, cost, production costs, etc. The effect itself does not mean production efficiency.

An indicator of the economic effect in the problem under consideration is the level of quality of construction products. Quality - equality or excess of actual indicators by directive ones.

The efficiency of the construction product quality management system is the ability to realize the goals for which this system has been created. In other words, the efficiency of the system is its effectiveness measured by the degree of implementation of the goals in the field of quality management of construction products [1-3, 4-9, 11-17.19-20]. 


\section{Materials and Methods}

The SP-methodology of the "club" type has emerged as an alternative to the development of "production" systems, when an individual is included in one or another activity, forming his ability to perform this activity by implementing special procedures: - creating and demonstrating gaps in the activity situations before an individual; $\bullet$ bringing the individual to the awareness of these gaps and setting targets for their elimination; $\bullet$ showcasing new means for eliminating gaps; $\bullet$ mastering new means and ways of activity. Systems built on the prototype of "production" do not allow a person to think differently than by identifying him with a certain structure of activity that is external with respect to a person, indicating the place he must occupy in this structure. Unlike "production", where organizational or management technical action is always directed at another person, at the "club", it can be directed only at himself: everyone is responsible only for his own action, since a person enters the "club" space as an autonomous person. The concept of "collective thinking" in the context of anthropotechnical technologies gives an ontological (philosophical doctrine of general categories and laws of being, existing in unity with the theory of knowledge and logic) substantiation of the "club" as a prototype of building open educational systems [1-3, 4-10].

\section{Results}

Vital activity is mainly provided by collectives in the habitat and is carried out by a variety of activities. It is advisable to introduce the Physiology-Environment-Activity (PEA) system (Figure 1) into consideration and systematically investigate three groups of parameters: P - physiology of an individual person; E - properties of the human environment; A - properties of human activity. The PEA triad is based on general assumptions about what different types of people are and what sets of characteristics and parameters are inherent in them. The formal "search" of various combinations of two spaces (a person, a group of people or their population on the one hand, and a habitat on the other) makes it possible to identify a specific typology of habits, opinions of people about themselves and their commitment to a particular activity. If we consider paired interrelations of components in the PEA system (for example, the interrelationship of $\mathrm{P}$ and A), then each time the third component of the system (in this case, E) appears to be uninvolved. In the design, most of the work is done this way: first, they design the project for the house, and then "tie" it to the site. If this fails, then the project of a house is designed again. That is, design exists separately from the environment as a combination of designers and technologies for their activities. Similar incidents can be observed in the housing and communal services. The management company and the contractor agreed among themselves to repair the roof of a residential building, without individually entering into contractual relations with the directly interested person - the tenant of the upper floor of the building (P). In case of various events due to the fault of the contractor (fires, leaks, physical damage, and etc.), the tenant of the upper floor is in the area of maximum risk. At the same time, he is legally generally not involved in the contractual relationship between the management company and the contractor (i.e. the interaction between $\mathrm{E}$ and $\mathrm{A}$ ) [1-3, 49]. 


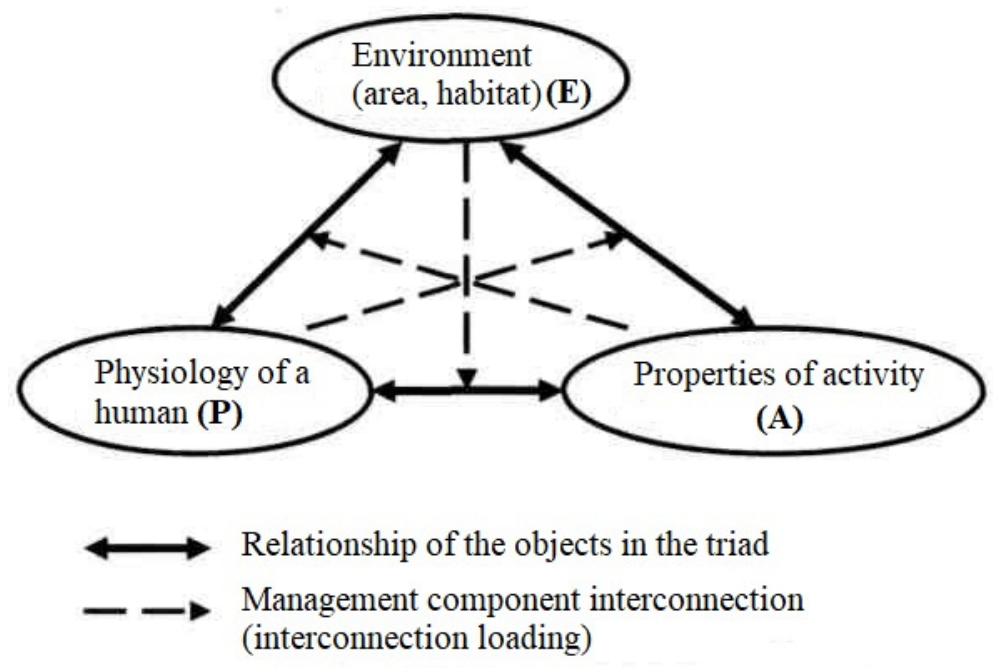

Fig. 1. Infographic model of the anthropotechnical approach to the construction of a basic typology of the system functioning (PEA).

Speaking about the advantages of BIM-design, it should be understood that the achievement of the desired result (accelerating the pace of construction, cost reduction, etc.) is possible only with the full transition of the industry to new technologies. Nowadays, the situation in the construction industry is such that in many cases, several contractors can work on the same facility. Some organizations are engaged in design, others are developing an architectural concept, and still others are engaged in engineering networks. Work on the facility is increasingly moving from the real world to the virtual one. Using a single concept is the key to successful cooperation between organizations. Improving the quality of construction and reducing its timeframe without substantial financial expenditures is one of the fundamental tasks of informational modeling technology of modern anthropotechnics $[4-9,10-15]$.

\section{Discussion}

In epistemology (genesis or development) of thinking, it is customary to present an "approach" as a manifesto (manifestum - appeal):

- an appeal or declaration containing a program and principles of activity;

- an expression of an opinion by a certain group of people.

It is possible to talk about an objectively existing "approach" when its fundamental differences from other well-known "approaches" are announced and substantiated. These differences are formulated in one of three epistemic spaces:

- in the paradigm (ontological pictures, diagrams and descriptions of objects);

- in syntagma (ways and methods of proof, argumentation, languages of description, explanation and understanding);

- in pragmatics (goals, values, tasks, prescriptions, permitted and prohibited forms of using the elements of syntagma and paradigm).

The contradiction and paradox of the "approach" phenomenon consists in its presence of activity and thinking both in a reflexed and non-reflective form. During the period of the formation of the "approach", it is well and clearly known that the ideas about the object and the object itself (as a special organization) set and determine not only its objective characteristics, but also the means and methods of thinking and human activity. In the 
period of operation, the recognized "approach", which became known, is forgotten. Methodological reflection is closed within the framework of the "approach" and it becomes non-fixable. Adherents (they can be determined not only by their attitude to the doctrine, personality or organization, but also by the degree of this attitude) of the "approach" subordinate their thinking and activity to an "epistemic machine" that defined by paradigm and syntagma, which can produce something new only within the framework of what is permitted by pragmatics. As a rule, any previously unknown innovations and modern technologies somehow first undergo criticism. Inertness and conservatism - these human qualities are often the factors that hinder progress.

The construction industry is no exception. Any new software for calculations, design, engineering, etc. always criticized by users. This is a logical process. In this case, wellestablished software certification and verification procedures help. Considering that buildings and structures are complex engineering objects, it is necessary to monitor the technical condition and functioning of various components - engineering networks, structures as a whole, and individual units, the behavior of the soil mass, etc. All these elements are interconnected and constitute a unified monitoring system for buildings and structures that unite a set of individual technical solutions. Important issues of creating a system are the problems of selection of equipment and techniques, their combination for monitoring the state of structures of the aboveground and underground parts of buildings and constructions, and foundation soils. Performance criteria monitoring is subject to system economic and mathematical modeling, in the formation of a system of adopted criteria. In practice, there are often situations where not all criteria have the same direction of optimization (i.e. all tend to either the minimum or the maximum). Particular criteria are formed mainly by two methods:

- Expert method - interview experts - processing the data obtained by methods of mathematical statistics with the definition of a compromise value;

- By an expert - a single person who makes a decision.

In order to maintain the quality management system at a high level, on the basis of information technologies, it is recommended to periodically reassess the efficiency of the element quality system - introducing target software to solve problems of life support and increase human comfort, taking into account changing environmental conditions.

Considering that there may be several criteria for assessing the efficiency, it is necessary to use multi-criteria methods when assessing the efficiency of the quality management monitoring system. Ensuring a comprehensive life safety through a variety of functional subsystems, which have a set of characteristics of the elements of quality systems identified when considering it from the standpoint of each of the varieties of construction reorganization, will provide the ability to simulate the main criteria for assessing the efficiency of the monitoring system for managing the quality of engineering systems of buildings and structures. The quality of construction products is influenced by the stability of technological processes, compliance with the correct technological sequence of work performance, coordinated actions of all departments of a construction organization and its subcontractors, rhythm of production, timely completeness, and a high degree of prefabrication of structures [1-3,4-9,11-19, 20].

The decomposition of the purposes of assessing the efficiency of the quality management monitoring system is shown in Figures 2,3. 


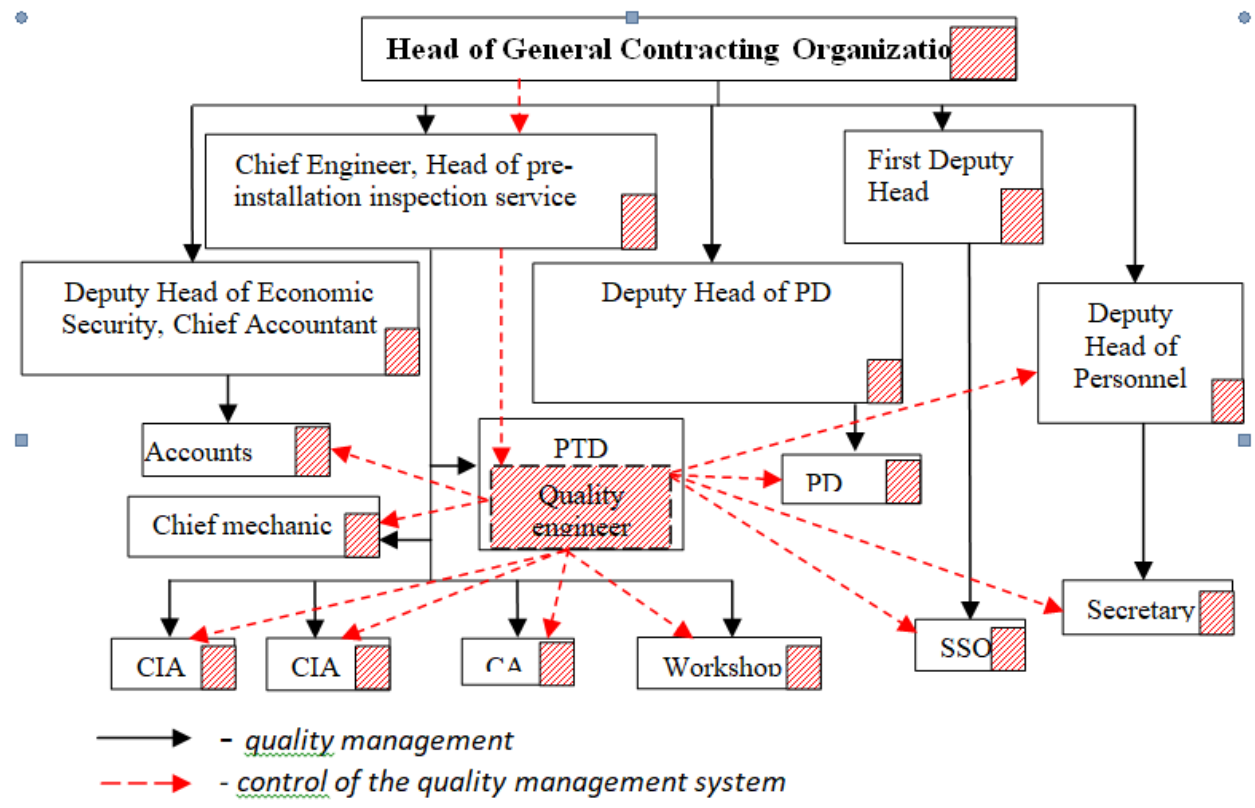

Fig. 2. Organizational structure of the quality management monitoring system.

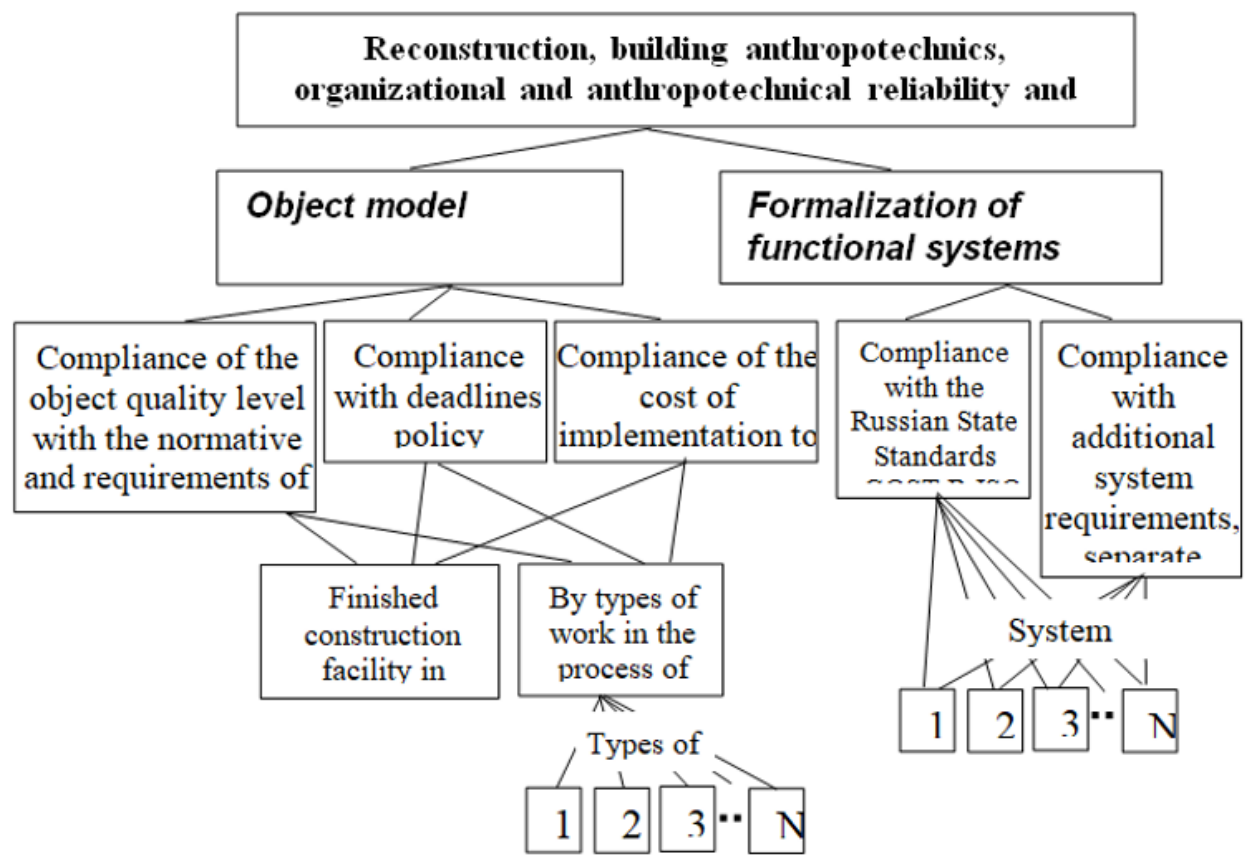

Fig. 3. Assessment of the efficiency of the quality management monitoring system. 


\section{Conclusion}

In the United States, the features of quality management experience are:

- tight quality control of manufacturing products using methods of mathematical statistics;

- attention to the process of production planning for volumetric and qualitative indicators, administrative control over the implementation of plans;

- improving the management of the company as a whole.

In the UK, when concluding a contract for the construction of buildings and structures, the customer requires the company to guarantee the quality of work - a written assurance that the contractor will apply an effective product quality control system. The quality control system provides for the maintenance of special documentation and reporting; conducting inspections to obtain objective data that the work, used materials and equipment meet the established control requirements. A construction contractor appoints a quality manager from among its members. The manager coordinates and monitors the functioning of the quality control system. In his activities, he reports to the technical director of the construction company and has the appropriate personnel of supervisors and inspectors. The functions of the manager include the compilation and distribution of quality manuals, the determination of the nature and extent of documentation on quality control. A quality control program is being drawn up for each facility.

An analysis of the results obtained in this paper showed that it is necessary to carry out corrective measures to increase the effectiveness of processes (analysis by the management, internal audit, management of documents and records, measurement of customer satisfaction, etc.). For a more thorough analysis of the economic efficiency of the system, processes and measures to improve them, it is necessary to allocate costs in these areas from the general financial statements. Considering the fact that this performance assessment is the first for this construction management, one can take this value as a base and use it for analysis in subsequent assessments - how much the system's performance indicators have improved or decreased. Existing elements of the quality management system for production processes and construction products showed that a fairly large amount of research on quality management has been completed today. Based on these studies, a regulatory framework for quality management has been created. However, the availability of such documents does not exhaust the problems in the effective management of the quality of construction products. The analysis identified a number of disadvantages:

1) there is no clear separation of the concepts of "quality management efficiency" and "quality management system";

2) efficiency is, as a rule, economic efficiency and overall effectiveness, while the concept of efficiency is broader than economic efficiency and effectiveness;

3) there are no unified approaches to solving the issue of assessing the efficiency of quality management systems for construction organizations;

4) there is no experience in assessing the efficiency of quality management systems in the organizational structures of construction production.

Nowadays, the need to monitor facilities and construction complexes (especially for structures) existing at the time of the suspension, as well as to analyze their condition at the time of resumption of construction with subsequent consideration of these changes in the project to ensure high requirements for the effectiveness of design developments, technological and organizational solutions, using economic and mathematical methods of modeling a system-target approach to assessing the management of elements in quality systems of construction production. BIM technologies should affect not only the processes of $3 \mathrm{D}$ modeling of building structures, but also the connection of modeling programs with information technologies of modern anthropotechnics [1-3, 4-9, 11-20]. 


\section{References}

1. R.R. Kazaryan, V.O. Chulkov, Sci Rev. Reg. so. asp. Impr. Cons. Pro. Qual., 24 (2015)

2. V.O. Chulkov, O.N. Kuzina Orgaizational-technological criteria of arrangement of construction renovation varieties, 410-426 (2010)

3. V.O. Chulkov, O.N. Kuzina, Retrieving - innovative direction in a functional system of construction renovation, 439-443 (2010)

4. A.A. Volkov, V.O. Chulkov, G.O. Chulkov, R.R. Kazaryan, O.N. Kyzina,. Collec. Rese. Pap. 9th Inte. Rese. pra. Con., part 2, 1065-1069, 2401-2404 (2015)

5. A.A. Volkov, V.O. Chulkov, G.O. Chulkov, R.R. Kazaryan, O.N. Kyzina, Rese. Pap. 9th Inte. Rese. pra. Con., part 2, 1065-1069, 2405-2408 (2015)

6. A.A. Volkov, V.O. Chulkov, G.O. Chulkov, R.R. Kazaryan, O.N. Kyzina, Rese. Pap. 9th Inte. Rese. pra. Con., part 3, 1065-1069, 2405-2408 (2015)

7. C. Gini, Stats The latest foreign statistical researches, 448 (2010)

8. A.A. Lapidus, H. Saydaev, L. Constr, Tech Org Influence of parameters of construction company organizational structure development on the generalized index of environmental load, 1 (2012)

9. A.G. Tamrazjan, N.V. Fedorova, Assessment of the hope of reinforced concrete structures, reinforced coal Technology of the textile industry, № 6, 226-231 (2016)

10. A.G. Tamrazjan, A.L. Zholobov, N.A. Ivannikova, Vestnik MGSU, № 11,125-130 (2012)

11. A. Slavin, S. Sinenko, N. Yoshin, The evolutionary development of the methodology of operational planning of construction production (2018)

12. S. Sinenko, A. Ahmetgaliev, A. Slavin, Practical aspects of construction of high-rise buildings in Russia (2018)

13. B. Zhadanovsky, S. Sinenko, The methodic of calculation for the need of basic construction machines on construction site when developing organizational and technological documentation (2018)

14. S. Novikov, B. Zhadanovsky, S. Sinenko, Theoretical basics and experimental methods of consideration of the concrete mixtures' movement resistance in the concrete-delivery pipelines (2018)

15. S. Novikov, B. Zhadanovsky, S. Sinenko, Guidelines on calculation of the concrete thermal treatment modes, (2018)

16. S. Sinenko, B. Zhadanovskiy, L. Pakhomova, Assessment Of Complex Technological Processes Of Concrete Mixes Preparation With On-Site Automated Concrete Mixing Plants (2018)

17. S.A. Sinenko, A.O. Feldman, Efficiency Perfection of Organizational-Technological Decisionson the Basis of Information Flows in the Construction of Multi-Storey Residential Buildings (2018)

18. S.A. Sinenko, B.V. Zhadanovskiy, S.A. Moiseeva, Experience of Concrete Works Execution by the Means of Air-Placed Concreting (2018) doi:10.1088/1757899X/463/4/042039 doi:10.1088/1757-899X/463/4/042039.

19. SX. Zeng, VWY. Tam, SM. Tam, Saf. Sci., Vol.46, No.8, 1155-1168 (2008) http://www.sciencedirect.com

20. E. Avdeeva, T. Davydova, N. Skripnikova, L. Kochetova, E3S Web of Conferences, 110 (2019) https://doi.org/10.1051/e3sconf/201911002139. 